\title{
Comparative Study of the Continuous and Batch Thermal Processing of $\mathrm{MgB}_{2}$ Wires
}

\author{
Bartek A. Glowacki (i), Mehmet Kutukcu, Serdar Atamert (i), Chris Dhulst ${ }^{(0)}$, Jan Mestdagh, \\ Wim Van Vooren, and Arend Nijhuis
}

\begin{abstract}
The last stage of the manufacturing process requires complex reactive diffusion formation process of $\mathrm{MgB}_{2}$ in the presence of $\mathrm{SiC}$ nanoparticles. Continuous thermal processing was adopted to produce long length $\mathrm{MgB}_{2}$ in situ wires with a homogeneous mixture of micron-sized $\mathrm{Mg}$, nanosized $\mathrm{B}$, as well as $\mathrm{SiC}$ dopant powders. This process has enabled the formation of $\mathrm{MgB}_{2}$ superconducting compound in a relatively short time. Traditional superconductor batch processing requires the wire batch to be heat treated in dedicated large furnaces. Additionally, such a batch process requires controllable slow heating-up, dwelling, and cooling down procedures to ensure uniformity of the superconducting properties along the wire length. Such a prolonged reactive diffusion process does require lower dwelling temperature and can potentially prevent full utilization of the doping materials, resulting in less effective pinning centers formation. On the other hand, continuous wire thermal processing enables rapid formation of the doped $\mathrm{MgB}_{2}$ with full utilization of the dopant. Also, in the continuous process, the moving thermal front brings complex dynamics to $\mathrm{Mg}-\mathrm{B}, \mathrm{C}-\mathrm{B}, \mathrm{Mg}-\mathrm{Si}$ interaction during $\mathrm{MgB}_{2}$ formation processes. The manuscript presents a comparative study of the reactive diffusion kinetics, the microstructural formation of the doped $\mathrm{MgB}_{2}$ compound, and their $J_{\mathrm{c}}(\mathrm{B}, \mathrm{T})$ characteristics.
\end{abstract}

Index Terms- $\mathrm{MgB}_{2}$ wires, superconducting cable, twisting, critical current, MRI, direct current (dc), gaseous helium cooling, continuous process, heat treatment.

\section{INTRODUCTION}

$\mathbf{T}$ HERE is an urgent need for cost effective manufacture and large quantities of $\mathrm{MgB}_{2}$ superconductors for a variety of applications working at the temperatures range of $15-20 \mathrm{~K}$ [1], [2]. Such a need puts a real pressure on the manufacturing capabilities of the traditional powder-in-tube (PIT) batch technology of multifilamentary $\mathrm{MgB}_{2}$ wires [3]. Our manufacturing technology stages of a single core conductor as well as $6+1$

Manuscript received October 29, 2018; accepted February 5, 2019. Date of publication February 19, 2019; date of current version March 22, 2019. (Corresponding author: Bartek A. Glowacki.)

B. A. Glowacki is with the Epoch Wires Ltd., Cambridge CB22 6SA, U.K., with the Institute of Power Engineering, 02-981 Warsaw, Poland, and also with the Department of Materials Science and Metallurgy, University of Cambridge, Cambridge CB3 0FS, U.K. (e-mail: bag10@cam.ac.uk; bartlomiej. glowacki@ien.com.pl; bartek.glowacki@epochwires.com).

M. Kutukcu and S. Atamert are with the Epoch Wires Ltd., Cambridge CB22 6SA, U.K.

C. Dhulst, J. Mestdagh, and W. Van Vooren are with NV Bekaert SA, BE 8550 Zwevegem, Belgium.

A. Nijhuis is with Faculty of Science \& Technology, University of Twente, 7500AE Enschede, The Netherlands.

Color versions of one or more of the figures in this paper are available online at http://ieeexplore.ieee.org.

Digital Object Identifier 10.1109/TASC.2019.2900351 architecture were presented in details in earlier publications respectively [4], [5]. This fabrication process has some similarities with other continuous-like processes reported in literature [6], [7].

Heat treatment of the long lengths of the wires can be conducted adopting two principally different reactive diffusion processes: continuous (on-line) and batch process. Both of these processes will enable formation of the $\mathrm{MgB}_{2}$ cores inside the in-situ conductors, but the question remains which one will be more economic and also which will provide the best critical current values for desired application. It has been proven that heat treatment of our wires with $\mathrm{SiC}$ does result in formation of the larger $\mathrm{MgSi}_{2}$ inclusions at moderately low temperatures $\sim 550{ }^{\circ} \mathrm{C}[8]$ and released carbon substitute $\mathrm{MgB}_{2}$, facilitating better performance of the conductor at elevated magnetic field. In case of batch process controllable slow heating-up, dwelling and cooling down procedures is required to ensure uniformity of the superconducting properties along the wire length. Such a prolonged reactive diffusion process does require lower dwelling temperature and can prevent full utilization of the doping materials, resulting in less effective pinning centres formation due to grain growth. Additionally, if the mass of the batch is substantial, the heating rate required will need to be correspondingly lower to ensure uniform reaction formation of $\mathrm{MgB}_{2}$. Therefore, target sintering temperature can be a misleading concept where formation of the $\mathrm{MgB}_{2}$ and other assisting reactions will place during ramping procedure in an incremental manner rather than sintering at the given temperature.

On the other hand, continuous wire thermal processing enables rapid heating up of the conductor resulting in fast formation of the doped $\mathrm{MgB}_{2}$ with full utilization of the dopant. High heating rates of undoped $\mathrm{MgB}_{2}$ were reported to lead to grain refinement [9]. Our previous investigations of the influence of heating rates and annealing temperatures on the $J_{\mathrm{c}}$ of nano-SiCdoped in situ monofilamentary $\mathrm{MgB}_{2} / \mathrm{Fe}$ wires revealed that higher $J_{\mathrm{c}}$ was obtained with slower heating rates, but the $J_{\mathrm{c}}$ is not very sensitive to annealing temperatures [10].

Our recent results conducted on $\mathrm{SiC}$ doped wires prove that critical current measurements of the $\mathrm{SiC}$ doped $\mathrm{MgB}_{2}$ wire after $10 \mathrm{~min}$ and $30 \mathrm{~min}$ sintering by rapid introduction of the wire to preheated furnace at temperature $700{ }^{\circ} \mathrm{C}$ show very similar values [5].

Also, our earlier research conducted on short duration annealing of in situ copper-cladded $\mathrm{MgB}_{2}$ wires (in range of $600{ }^{\circ} \mathrm{C}-750{ }^{\circ} \mathrm{C}$, with heating ramp rate of $150{ }^{\circ} \mathrm{C} / \mathrm{min}$ ) show 


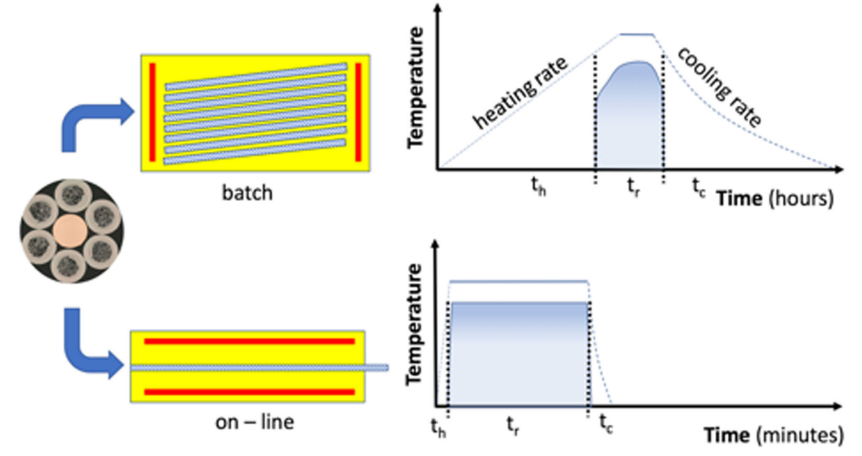

Fig. 1. Schematic illustration of the two different heat treatment procedures (batch and on-line) of $\mathrm{MgB}_{2}$ formation in twisted multifilamentary $\mathrm{MgB}_{2}$ conductor (under protective gas atmosphere). Schematic plots of heat treatment stages for batch and on-line procedures are described in Table I. $t_{\mathrm{h}}$ time of heating, $t_{\mathrm{r}}$ reaction time and $t_{\mathrm{c}}$ is a cooling time. Graded areas under $T(t)$ profiles represent schematically the variable kinetic of formation of $\mathrm{MgB}_{2}$. It is evident that the definition of the actual reaction time and therefore effective reactive diffusion process of $\mathrm{MgB}_{2}$ phase formation in batch process is much more complex in comparison to on-line process.

that the microstructure and properties of the wires are strongly dependent on the heat treatment temperature and ratebut are quite insensitive to the reaction time: a short heat treatment for 5 min at $700{ }^{\circ} \mathrm{C}$ was sufficient for obtaining the highest critical current achieved [9]. The possibility of using lower reaction temperatures and durations may also offer an opportunity for reducing the extent of grain coarsening, resulting in finer grains and enhanced flux pinning.

Results of $\mathrm{Fe}$ in-situ sheathed wires doped with nano-SiC particles sintered at temperatures ranging from $580{ }^{\circ} \mathrm{C}$ to $1000{ }^{\circ} \mathrm{C}$ for 5-30 min with heating rate of $10^{\circ} \mathrm{C} / \mathrm{min}$ shown that samples sintered at a lower temperature have a very fine and well consolidated grain structure while samples sintered at a high temperature contain large grains with easily distinguishable grain boundaries [11]. Low temperature sintering resulted in a higher concentration of impurity precipitates, larger resistivity, higher $J_{\mathrm{c}}$ up to $15 \mathrm{~T}$ and lower $T_{\mathrm{c}}$ values.

The influence of different heating rates, on the microstructure and superconducting properties of the undoped $\mathrm{MgB}_{2}$ bulk was reported in literature and no obvious variation in the grain size was found except for the changes in morphologies [12]. This brings necessity to further investigate the differences between continuous (on-line) and batch process it in the wire forms.

However, there is a significant difference between rapid heating and rapid cooling of the short pieces of the wire which are introduced directly into the preheated furnace and continuous on-line annealing of long lengths of the wires.

In on-line processing there is a risk of creating a thermal front that can potentially bring complex dynamics to reactive diffusion processes between $\mathrm{Mg}-\mathrm{Si}, \mathrm{Mg}-\mathrm{B}, \mathrm{C}-\mathrm{B}$ interaction during $\mathrm{MgB}_{2}$ formation processes, resulting in more complex percolative $\mathrm{MgB}_{2}$ formation [13]. Therefore, presented research will address the above issues.

In this manuscript we will be investigating the possible differences in the conductor properties under two principally different reactive diffusion processes: continuous (on-line) and batch process.
TABLE I

Sintering PRocedures of Wires at REACTION TEMPERATURE $700{ }^{\circ} \mathrm{C}$

\begin{tabular}{ccccc}
\hline \hline $\begin{array}{c}\text { Total heat } \\
\text { treatment } \\
\text { time }\end{array}$ & $\begin{array}{c}t_{\mathrm{h}} \\
(\mathrm{min})\end{array}$ & $\begin{array}{c}t_{\mathrm{r} \text { at 7000C }} \\
(\mathrm{min})\end{array}$ & $\begin{array}{c}t_{\mathrm{c}} \\
(\mathrm{min})\end{array}$ & comment \\
\hline $\mathrm{S} 1-12$ & 2 & 8 & 2 & direct insertion \\
$\mathrm{S} 1-32$ & 2 & 28 & 2 & $\begin{array}{c}\text { direct insertion } \\
\text { on-line }\end{array}$ \\
$\mathrm{S} 2-10$ & 1.5 & 7 & 1.5 & $\begin{array}{l}\text { on-line } \\
\text { S2-20 }\end{array}$ \\
$\mathrm{S} 2-30$ & 5 & 14 & 3 & ontine \\
$\mathrm{S} 3-1200$ & 420 & 20 & 5 & batch \\
\end{tabular}

\section{Heat Treatment}

\section{A. Heat Treatment Procedures}

Consideration is given to both continuous (on-line) and batch process as presented schematically in Fig. 1.

As presented in Table I we have investigated three different procedures where the maximum sintering temperature in the presented cases was chosen to be $700{ }^{\circ} \mathrm{C}$. S1, wires were rapidly heated by direct insertion to preheated furnace chamber; S2, wires were on-line thermally processed continuously as schematically is presented in Fig. 1. S3 wire was inserted into the furnace chamber at room temperature (RT) and heated to $700{ }^{\circ} \mathrm{C}$, at rate of $100{ }^{\circ} \mathrm{C} \mathrm{h}^{-1}$ and subsequently cooled to RT. $I_{\mathrm{c}}$ results of all three treatment procedures should provide the answer if the on-line processing will be the acceptable or even preferential technique.

All investigated in situ $\mathrm{MgB}_{2}$ wires ( $\mathrm{OD}=0.75 \mathrm{~mm}$ and superconductive powder cross-sectional filling factor $=30 \%$ ) were prepared using mixture of $\mathrm{B}-\mathrm{Mg}-\mathrm{SiC}$ [5]. Amorphous boron from Pavezyum, Turkey, magnesium from Magnesium

Metal Co., Turkey and SiC dopant from Iolitec, Germany. Amorphous boron has a purity of 95-97\% with a narrow particle size distribution with majority at $0.2 \mu \mathrm{m}$ also minority at $2 \mu \mathrm{m}$ and some at $7 \mu \mathrm{m}$ as presented in [5]. Magnesium has a purity of above $99.9 \%$ with a particle size of $100-150 \mu \mathrm{m}$ and nano$\mathrm{SiC}$ has a particle size of $40-60 \mathrm{~nm}$. SiC doping level was kept constant at the level of $10 \% \mathrm{SiC}$. During the mixing process oxygen, hydrogen and moisture levels were monitored [5]. In the continuously manufactured $\mathrm{SiC}$ doped in situ $\mathrm{MgB}_{2}$ wire made from 100-150 $\mu \mathrm{m}$ size $\mathrm{Mg}$ powder and nanosized boron there is formation of the $\mathrm{Mg}_{2} \mathrm{Si}$ micro-inclusions in the body of the wire in addition to elongated larger $\mathrm{Mg}_{2} \mathrm{Si}$ inclusions, localized in position of original elongated Mg ribbons.

\section{Critical Current Measurements}

\section{A. Helium Force Vapor Cooled Critical Current Testing of Wires}

The transport critical current of the sheathed wires was measured in an efficient helium gas force vapor cooled bespoke system [14] in a uniform magnetic flux density of $1 \mathrm{~T}$. Measurements were conducted using an electric field criterion of $E=1 \mu \mathrm{V} \cdot \mathrm{cm}^{-1}$. Sample voltage contacts were placed $1 \mathrm{~cm}$ apart. Wire lengths of $14 \mathrm{~cm}$ were used for testing to ensure that 


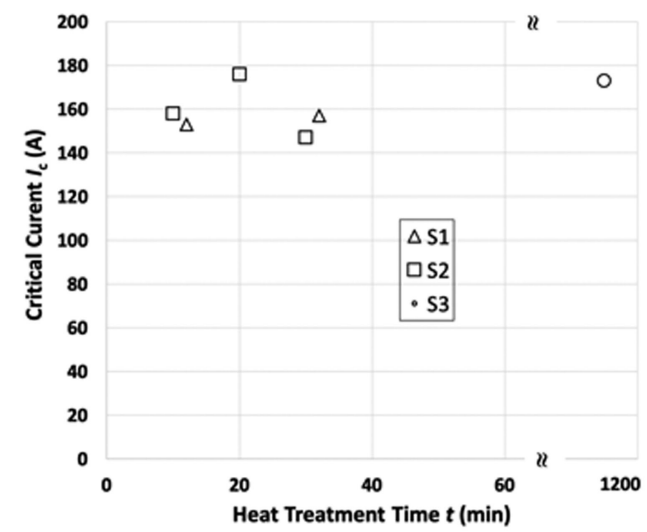

Fig. 2. Comparison of critical current values of metal sheathed $\mathrm{MgB}_{2}+10$ wt $\% \mathrm{SiC} 0.75 \mathrm{~mm}$ wires after sintering according to $\mathrm{S} 1, \mathrm{~S} 2$ and $\mathrm{S} 3$ procedures described in Table I. Measurements were conducted under magnetic field of 1 Tesla at $20 \mathrm{~K}$ [14].

all current is transferred from the sheath to the superconducting core. Current contacts were $4 \mathrm{~cm}$ long.

\section{B. Procedure S1}

Critical current measurements of the wire sintered according to procedure $\mathrm{S} 1$ after $8 \mathrm{~min}$ and $28 \mathrm{~min}$ sintering at $700{ }^{\circ} \mathrm{C}$ Critical current measurements of the wire sintered according to procedure $\mathrm{S} 1$ after $8 \mathrm{~min}$ and $28 \mathrm{~min}$ sintering at $700{ }^{\circ} \mathrm{C}$ (sample S1-12 and S1-32 respectively) show almost identical values see Fig. 2 providing evidence that short time sintering presents a credible possibility for the rapid wire sintering. These results can be also supported by our earlier measurements conducted on wires with different metal sheets [5].

\section{Procedure $S 2$}

The result of a typical wire sintered on-line according to procedure S2 (described in Table I) shows a similar critical current value to the samples measured according to $S 1$ procedure, Fig. 2. Also, among three on-line $\mathrm{S} 2$ wires a maximum $I_{\mathrm{c}}$ value was achieved for S2-20 sample.

\section{Procedure S3}

As it was discussed earlier, see Fig. 1, the variable kinetic of formation of $\mathrm{MgB}_{2}$ is an inherent part of the batch procedure (S3). As result, it becomes evident that the definition of the actual reaction time and therefore effective reactive diffusion process of $\mathrm{MgB}_{2}$ phase formation in batch process is much more complex in comparison to on-line process. Considering that the first reaction of $\mathrm{MgB}_{2}$ takes place at $\sim 620{ }^{\circ} \mathrm{C}$ we have conducted initial preliminary estimation of the $t_{\mathrm{h}}, t_{\mathrm{r}}$ and $t_{\mathrm{c}}$ parameters to be used in S2-20 to result in a similar degree of reactive diffusion and grain growth as in S3-1200, see Table I. Comparative critical current measurements conducted at $20 \mathrm{~K}$ and $1 \mathrm{~T}$ revealed that the critical current value achieved for sample S3-1200 was identical as achieved for S2-20 wire. In our procedure S3-1200 formation of $\mathrm{MgB}_{2}$ was conducted at both, solid-state and liquid-state reactive diffusion processes of $\mathrm{MgB}_{2}$ formation, therefore further research is required to define
TABLE II

SERIES OF On-Line SINTERED SAMPLES ACCORDING TO PROCEDURE S2

\begin{tabular}{|c|c|c|c|c|}
\hline $\begin{array}{l}\text { Total heat } \\
\text { treatment } \\
\text { time }\end{array}$ & $\begin{array}{c}t_{\mathrm{h}} \\
(\mathrm{min})\end{array}$ & $\begin{array}{l}t_{\mathrm{r} \text { at } 700 \circ \mathrm{C}} \\
(\mathrm{min})\end{array}$ & $\begin{array}{c}t_{\mathrm{c}} \\
(\mathrm{min})\end{array}$ & comment \\
\hline S2-5 & 2 & 1 & 2 & simulation on-line \\
\hline S2-7 & 2 & 3 & 2 & simulation on-line \\
\hline S2-12 & 2 & 8 & 2 & simulation on-line \\
\hline $\mathrm{S} 2-32$ & 2 & 28 & 2 & simulation on-line \\
\hline
\end{tabular}

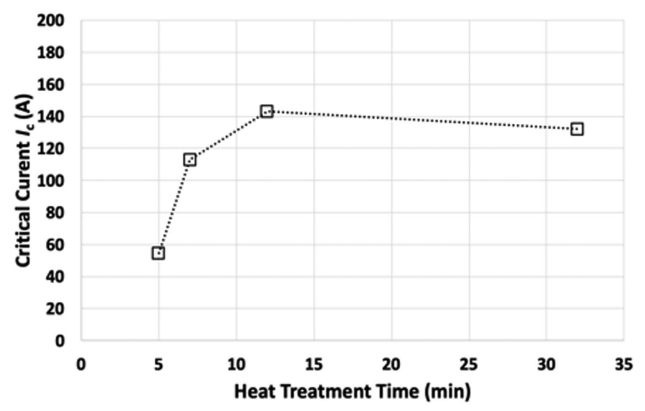

Fig. 3. Comparison of critical current values of metal sheathed $\mathrm{MgB}_{2}+10$ $\mathrm{wt} \% \mathrm{SiC} 0.75 \mathrm{~mm}$ wires sintered using simulation on-line according to procedure S2 listed in Table II for the total heat treatment time of 5, 7, 12 and $32 \mathrm{~min}$, measured at $4.2 \mathrm{~K}$ and magnetic flux density of 3 Tesla, see Table II.

thermal division between solid-state and liquid-state reactive diffusion processes of $\mathrm{MgB}_{2}$ formation, influencing transport critical current properties of the conductor heat treated as a batch.

\section{E. Liquid Helium Cooled Critical Current Measurements of On-Line Sintered Wires}

To define importance of dynamic on-line sintering parameters such as: time of heating, $t_{\mathrm{h}}$, reaction time, $t_{\mathrm{r}}$, and cooling time, $t_{\mathrm{c}}$, series of experiments according to procedure S2 were conducted, listed in Table II. Wires described in Table II were continuously inserted into the tubular furnace to simulate on-line process.

The critical current measurements of the $\mathrm{S} 2$ wires listed in Table II were conducted in a uniform magnetic flux density of $3 \mathrm{~T}$ at liquid helium using an electric field criterion of $E=$ $1 \mu \mathrm{V} \cdot \mathrm{cm}^{-1}$. The $I_{\mathrm{c}}\left(t_{\mathrm{r}}\right)$ results are presented in Fig. 3. It is evident that 8 minutes reaction time at $700{ }^{\circ} \mathrm{C}(\mathrm{S} 2-12)$ was sufficient to achieve the best performance at $3 \mathrm{~T}$.

\section{CONCLUSION}

The critical current values of rapidly heated wires show that production of the long lengths of the superconductive $\mathrm{MgB}_{2}$ wires with narrow particle distribution of boron and magnesium, enabling formation of $\mathrm{MgB}_{2}$ superconducting compound in a relatively short time, is a viable solution to achieve low cost $\mathrm{MgB}_{2}$ wires. Additionally, there is a scope for further improvement of our $\mathrm{MgB}_{2}$ wires once used $\mathrm{Mg}$ particles size will be $\sim 30 \mu \mathrm{m}$, that way, substantially improving uniform spread of 
the $\mathrm{Mg}_{2} \mathrm{Si}$ inclusions, enhancing an effective volume pinning force at higher magnetic flux densities.

In on-line processing of our $\mathrm{Mg}-\mathrm{B}-\mathrm{SiC}$ wires, where thermal front could potentially bring complex dynamics to reactive diffusion processes between $\mathrm{Mg}-\mathrm{Si}, \mathrm{Mg}-\mathrm{B}, \mathrm{C}-\mathrm{B}$ interaction during $\mathrm{MgB}_{2}$ formation processes, resulting in more complex percolative $\mathrm{MgB}_{2}$ formation we have seen similar $I_{\mathrm{c}}$ performance compared to batch sinter processing.

However, future in depth analysis will be conducted to define conditions at which such effect may occur and in order to further optimize on-line heat treatment conditions of our $\mathrm{MgB}_{2}$ conductor production. Presented results therefore clearly offer the opportunity for on-line thermal treatment process that can be adopted in large-scale production rather than the usual batch heat treatment process.

Comparative critical current measurements conducted, indicate that further research is required to define thermal division between solid state and liquid state reactive diffusion processes of $\mathrm{MgB}_{2}$ formation. Such research will reveal which of the on-line or batch formation microstructures will be more suitable for application in MRI machines operating at $3 \mathrm{~T}$.

\section{REFERENCES}

[1] B. A. Glowacki, "Hydrogen cryomagnetics: The way forward for superconductivity," in Proc. 23rd Int. Cryogen. Eng. Conf. Int. Cryogen. Mater. Conf., 2011, pp. 353-357.

[2] B. A. Glowacki, W. J. Nuttall, and R. H. Clarke, "Beyond the helium conundrum," IEEE Trans. Appl. Supercond., vol. 23, no. 3, Jun. 2013, Art. no. 0500113 .
[3] G. Grasso et al., "Fabrication and properties of monofilamentary $\mathrm{MgB}_{2}$ superconducting tapes," Supercond. Sci. Technol., vol. 16, pp. 271-275, 2003.

[4] S. Atamert, M. N. Kutucku, J-L Scandella, A. Baskys, Z. Zhong, and B. A. Glowacki, "Novel superconducting $\mathrm{MgB}_{2}$ wires made by continuous process," IEEE Trans. Appl. Supercond, vol. 26, no. 3, Apr. 2016, Art. no. 6201104.

[5] M. N. N. Kutukcu et al., "Composite superconducting $\mathrm{MgB}_{2}$ wires made by continuous process," IEEE Trans. Appl. Supercond., vol 28, no 4, Jun. 2018, Art. no. 6200704.

[6] Y. C. Guo, P. A. Bain, H. K. Liu, S. X. Dou, and E. W. Collings, "High$\mathrm{T}_{\mathrm{c}}$ superconducting wires and tapes prepared by "continuous tube forming/filling (CTFF)" technique," Adv. Cryogen. Eng., vol. 42, pp. 701-708, 1996.

[7] M. Tomsic et al., "Development of magnesium diboride $\mathrm{MgB}_{2}$ wires and magnets using in situ strand fabrication method," Physica C, vol. 456, no. 1/2, pp. 203-208, Jun. 2007.

[8] B. Sun, S. Li, H. Imai, J. Umeda, and K. Kondoh, "Synthesis kinetics of $\mathrm{Mg}_{2} \mathrm{Si}$ and solid-state formation of $\mathrm{Mg}-\mathrm{Mg}_{2} \mathrm{Si}$ composite," Powder Technol., vol. 217, pp. 157-162, 2012.

[9] M. Woźniak, S. C. Hopkins, and B. A. Glowacki, "Study of short duration heat treatments of an in situ copper-sheathed $\mathrm{MgB}_{2}$ wire," Supercond. Sci. Technol., vol. 23, no. 10, Oct. 2010, Art. no. 105009.

[10] S. K. Chen et al., "Effect of heating rates on superconducting properties of pure $\mathrm{MgB}_{2}$, carbon nanotube and nano-SiC doped in situ $\mathrm{MgB}_{2} / \mathrm{Fe}$ wires," Appl. Phys. Lett., vol. 87, 2005, Art. no. 182504.

[11] S. Soltanian et al., "High transport critical current density and large $\mathrm{H}_{\mathrm{c} 2}$ and $\mathrm{H}_{\mathrm{irr}}$ in nanoscale $\mathrm{SiC}$ doped $\mathrm{MgB}_{2}$ wires sintered at low temperature," Supercond. Sci. Technol., vol. 18, pp. 658-666, 2005.

[12] Q. Zhao, Y. Liu, Y. Han, Z. Ma, Q. Shi, and Z. Gao, "Effect of heating rates on microstructure and superconducting properties of pure $\mathrm{MgB}_{2}$," Physica C, vol. 469, pp. 857-861, 2009.

[13] Z. Ma and Y-C. Liu, "Low-temperature synthesis of $\mathrm{MgB}_{2}$ superconductors," Inter. Mater. Rev., vol. 56, pp. 267-286, 2011.

[14] A. Baskys, S. C. Hopkins, J. Bader, and B. A. Glowacki, "Forced flow He vapor cooled critical current testing facility for measurements of superconductors in wide temperature and applied magnetic field range," Cryogenics, vol. 79, pp. 1-6, 2016. 